\title{
Plant Secondary Metabolites in Nectar: Impacts on Pollinators and Ecological Functions
}

Philip C. Stevenson ${ }^{1 \& 2}$

Susan W. Nicolson ${ }^{3}$

Geraldine A. Wright ${ }^{4}$

*Correspondence author: p.stevenson@kew.org, +442083325377

${ }^{1}$ Royal Botanic Gardens, Kew, Surrey TW9 3AB, UK

${ }^{2}$ Natural Resources Institute, University of Greenwich, Kent, ME4 4TB, UK

${ }^{3}$ Department of Zoology \& Entomology, University of Pretoria, Private Bag X20, Hatfield 0028, South Africa

${ }^{4}$ Centre for Behaviour and Evolution, Institute of Neuroscience, Newcastle University, Newcastle upon Tyne, NE1 7RU, UK

\section{Summary}

1. The ecological function of secondary metabolites in plant defence, against herbivores is well established, but their role in plant-pollinator interactions is less obvious. Nectar is the major reward for pollinators, so the occurrence of defence compounds in the nectar of many species is unexpected. However, increasing evidence supports a variety of potential benefits for both plant and pollinator from these components. 
2. Secondary metabolites in nectar can be toxic or repellent to flower visitors, but they can also go undetected or make nectar attractive . For example, caffeine in nectar improves pollinator memory for cues associated with food rewards and enhances pollen transfer. All of these effects depend on the concentration of nectar metabolites so should be evaluated experimentally at a range of ecologically relevant doses.

3. Beneficial effects may include the following: a) increasing specialization in plantpollinator interactions, b) protecting nectar from robbery or larceny, and c) preservation of nutrients in nectar from microbial degradation and reducing microbial disease levels in flower visitors.

4. This review synthesises evidence from recent literature that supports selection for secondary metabolites in floral nectar as an adaptation that drives the co-evolution between plants and their pollinators. However, their presence in nectar could simply be a consequence of their occurrence elsewhere in the plant for defence (pleiotropy). We draw attention to the need for studies demonstrating benefits to the plant, the importance of levels of exposure and a effects on target species beyond the current emphasis on alkaloids and bees.

\section{Toxic nectar: adaptive function or pleiotropy}

Plants produce secondary metabolites that accumulate in plant tissues for a variety of functions but primarily for defence against herbivores, fungi and bacteria and as plant signals (Schoonhoven et al. 2005). The term secondary metabolite describes natural chemicals produced by plants, fungi and other organisms that are not used in primary metabolic pathways (Pichersky and Gang 2000). However, their roles in other plant functions are specific, variable and 
numerous, with perhaps 100,000 or more structures likely (Verpoorte 2000). Typically characterised as low molecular weight organic compounds, their distribution is often restricted to just a few species or genera, suggesting specific adaptations to specific functions. Their importance as regulated defence systems in their interactions with insect herbivores, especially as toxins or repellents, has been well established through decades of research (Fraenkel 1959; Whittaker and Feeny, 1971; Berenbaum,1995; Agrawal and Weber 2015).

Optimal defence theory predicts a correlation between the value of tissue and the level of defence such that the distribution of defensive chemicals within a plant may be restricted to critical tissues (McCall and Fordyce, 2010; Cook et al., 2013). However, toxic or repellent secondary metabolites also occur in floral nectar where their role is less obvious because nectar is a reward for polliantors (Table 1) (Pacini and Nepi 2007; Detzel and Wink 1993; Manson et al. 2013; Tiedeken et al. 2016; Irwin et al. 2014). It is possible that their occurrence in nectar is regulated for ecological functions: to enhance pollination service or protect the flower and/or pollinator rewards (Table 1) (Adler 2001; Irwin et al., 2014; Manson et al. 2012).

Alternatively, defence compounds are under selection by plant antagonists and may occur in nectar during nectar production (Adler, 2001). Selection in this case might favour plants that keep secondary metabolites out of nectar; recent work suggests their concentrations in nectar are lower than in other plant parts (Cook et al., 2013). At present, there is little evidence indicating secondary metabolites in nectar co-evolved with pollinators. Instead, it is more parsimonious to suppose that adaptive functions may arise after plants have been selected for the production of 
toxins as defences against plant antagonists. Rather than imposing selection for the production of novel secondary metabolites, pollinators are more likely to impose selection on the concentrations of defensive metabolites that wind up in nectar and pollen. Pollinators impose selection pressure on plants, especially on floral traits, so it is reasonable to expect that pollination and chemical defence may not necessarily have always evolved independently (Campbell et al. 2015; Adler 2001). For example, outcrossing species of Nicotiana sp. produce less nicotine in nectar, flower and leaf tissue than self-compatible species, suggesting that selection against flower toxins also affects their defensive function. In this example, selection by mutualists for nicotine-free nectar outweighs selection for nicotine-laced leaves by antagonists (Adler et al. 2012).

Pollination in most angiosperms requires the services of pollinators for which they are typically rewarded (Kevan and Baker 1983; Raguso and Willis 2005). Attraction and fidelity to a particular plant species, however, is enhanced by the co-occurrence of nectar and floral traits such as odours (Wright and Schiestl 2009; Kessler et al. 2015a). So, it is conceivable that nonvolatile nectar secondary metabolites might also act as attractants and cues for pollinators, thus acting as chemical filters, or enhance pollination behaviours (Couvillon et al. 2015).

We propose a revised framework categorising effects on pollinators and ecological roles of secondary metabolites in nectar around broad biological activities and functions in the light of recent research. After discussing the occurrence of secondary metabolites in nectar, we review research on their effects under two broad themes: (1) impact on the behaviour of pollinators, 
which has consequences for pollinator specialization and filtering (including protection against nectar robbery or larceny); and (2) antimicrobial activities that may maintain nectar quality or ameliorate diseases. We also consider how pollinators cope with toxic secondary compounds after ingestion. Finally, we identify areas of focus for future research.

\section{Occurrence of secondary metabolites in nectar}

How secondary metabolites arrive in nectar is unclear (Heil 2011). They could be transported from phloem or xylem through nectary cells in a similar way to carbohydrates. In buckwheat, trichomes in nectary glands secrete sugars into nectaries from phloem via nectary parenchyma (Cawoy et al. 2008). Secondary metabolites biosynthesised elsewhere in the plant could be secreted into nectar in a similar way. In irises, Lohaus \& Schwerdtfeger (2014) found the same iridoid glycosides in the nectar and phloem sap of two different species, suggesting that iridoids may indeed leak passively into nectar. Furthermore, the nectar, anthers, corollas, stems and pollen of Delphinium sp. contain similar alkaloids differing only in their concentration, suggesting a similar origin (Cook et al. 2013). More recently, Anton and Kaminska (2015) proposed differing mechanisms in Ranunculaceae. Nectar in Consolida regalis and Delphinium elatum is exuded through micro-channels in the nectary cuticle, whereas in Aconitum lycoctonum and Aquilegia vulgaris nectar results from rupturing of nectary cell walls and the release of the entire cytoplasmic content of the cell into the nectary cavity. This may explain where corolla and nectar chemistry are similar (Lohaus and Schwerdtfeger 2014; Cook et al. 2013). While are few examples addressed this issue, the phloem and xylem contribution to nectar clearly varies across taxa (Nepi 2007) so their origins will also likely vary across species. Currently we do not 
know how phloem and nectar are related or how metabolites transport into nectar or are excluded from it (Pate et al. 1985).

The assumption that the content of nectar arises directly from phloem may, however, be too simple (Orona-Tamayo et al. 2013). Studies showing differences in nectar, pollen and floral chemistry indicate that plants can regulate these compounds in specific tissues (Irwin et al. 2014; Manson et al. 2012). Examples of tissue specific accumulation of defensive secondary metabolites are known (McCall and Fordyce 2010; McKey 1974). However, Adler et al. (2006) reported that herbivory by a moth caterpillar increased concentrations of the defence compound, anabasine, in nectar but not in leaves and could result from tissue specific regulation in roots and transport to nectar via phloem that does not impact anabasine expression in leaves. Nicotine concentrations in nectar and other tissues of Nicotiana species are correlated but lower across all plant parts in outcrossing species (Adler et al. 2012). However, in N. africanum, the concentrations of nornicotine in leaves did not predict the concentrations in nectar where nicotine and its derivatives were absent (Marlin et al. 2014). Exclusion of compounds from phloem is also reported and illustrated by the limonoid nomilin found in Citrus which is biosynthesised in the phloem region of stem tissues (Ou et al. 1988) and then translocated to leaves, fruit and seeds, where it is further modified (Hasegawa et al., 1986). In contrast, limonoids are not found in Citrus nectar (Fig 1). Furthermore, caffeine occurs as the only secondary metabolite in nectar of Coffea species (Wright et al. 2013) whereas numerous other compounds occur in other floral tissues (Fig 2). In another example, the corollas of Rhododendron ponticum contain a variety of compound classes (Egan 2015) whereas the nectar 
contains primarily grayanotoxins (Egan et al. 2016). So while there is some evidence supporting nectar specific regulation, more work is needed.

Variability in the presence and concentration of nectar secondary metabolites is also an important but often overlooked parameter. Nectar secondary metabolites vary across time, them even within a plant (Kessler et al. 2012; Irwin et al. 2014; Cook et al. 2013). Ecological explanations of nectar compounds are less certain where expression of chemicals is so variable. When Kaczorowski et al. (2014) measured nectar alkaloids of N. glauca, they found that the average concentrations of anabasine and nicotine were two orders of magnitude lower than in a previous study (Tadmor-Melamed et al. 2004). Kessler et al. (2012) also reported high variability in nicotine concentrations in a species of Nicotiana but provided evidence that variation in nectar nicotine was itself the underlying cause of the pollinator behaviour modifying effect. High variation in caffeine concentrations has been reported in Coffea and Citrus flower nectars but experimental protocols covered all ecologically relevant concentrations and natural quantities were always within the concentration range for behaviour modifying effects on honeybees (Wright et al. 2013). Some studies investigate effects of only a single concentration which could provide misleading outcomes depending on how ecologically relevant that concentration is. Studies on dose-response relationships, such as that of Manson et al. (2013), would provide more robust evidence for effects. Future studies need to focus on whole plant chemistry, the influence of herbivory (e.g., Adler et al. 2012). and spatial and temporal variation of nectar secondary metabolites (Egan et al. 2016). 


\section{Nectar chemicals mediating behaviour of pollinators}

The impact on pollinator behaviour is likely to be the main source of selection against the occurrence of secondary metabolites in nectar. Because pollinators visit flowers to acquire food, most learn to associate floral reward quality with colours, scents, shape and location. Just as they learn to find flowers with high quality or abundant nectar, they can also learn to avoid visiting flowers with nectar containing toxic secondary compounds (Gegear et al. 2007; Wright et al. 2010). Their mechanisms for doing this include association of floral traits with the taste of secondary metabolites in nectar or with the post-ingestive consequences of accidentally ingesting such compounds if they are toxic (Wright et al. 2010).

The best examples of pollinators learning to reject flowers with the taste of toxins are from bees. For example, bumblebees (Bombus impatiens and B. terrestris) given a choice of a yellow flower associated with sucrose solution or a blue flower with sucrose solution containing the alkaloids gelsemine or quinine, choose the yellow flowers (Gegear et al. 2007; Avargues-Weber et al. 2010). In a proboscis extension assay for associative learning, restrained honeybees trained to associate a food reward with an odour learn to avoid extending their proboscis to the odour when the sucrose reward contains quinine (Wright et al. 2010). Likewise, free-flying honeybees learn to avoid taking food from feeders treated with high concentrations of alkaloids or other toxins (Singaravelen et al. 2005). Moths (Heliothis virescens) can also learn to avoid odours associated with quinine in food (Jorgensen et al. 2007).

When a pollinator visits a flower, its proboscis is often the first body part to contact nectar. The first response of an insect pollinator to toxins in nectar, therefore, is likely to be due to detection 
of secondary metabolites by gustatory neurons in the mouthparts. Insect pollinators accomplish this using gustatory sensilla that house neurons that respond to sugars, salts, acids, water and to non-nutrient compounds (Inoue et al. 2009; Omura et al. 2008; Wright et al. 2010). When neurons in this location detect toxic or bitter substances such as secondary metabolites, this leads pollinators to reject food. For example, when bees detect substances like quinine or nicotine in sucrose solutions, they will reject food or consume less (Wright et al., 2010). Rejection of foods containing alkaloids is clearly seen when the feeding behaviour itself is assayed; restrained honeybees retract the proboscis when quinine laced sucrose is placed at its tip (Wright et al. 2010). This response depends on the toxin, the pollinator species, and on whether the animal is hungry (Wright et al. 2010). The responses to toxins in nectar are attenuated by the concentration of sugars; solutions high in carbohydrates are less likely to be rejected even when toxins are present (Gegear et al. 2007, Köhler et al. 2012, Lerch-Henning \& Nicolson 2013).

Secondary metabolites can also be phagostimulatory to insect pollinators, but this seems to be limited to insects that specialise on feeding on toxic plants as larvae. Adult hawkmoths (Manduca sexta) find low concentrations of caffeine or lobelline phagostimulatory when they are presented to the mouthparts (Reiter et al. 2015). Other lepidopteran adults that specialise on consuming plants with highly toxic alkaloids, such as the danaid butterfly, Euploea mulciber, also find alkaloids from their host plants phagostimulatory (Honda et al. 2006).

Toxicity of secondary compounds is typically a function of their concentration but it is important to note that they may not always be detected even at toxic levels. An example is the cyanogenic 
glycoside amygdalin, found in the nectar of almond flowers (London-Shafir et al. 2003).

Honeybees do not detect this compound in sucrose solutions, and in fact will drink

concentrations high enough to kill them (Wright et al. 2010; Sanchez et al., 2010). Another study

of honeybees found that they unwittingly share solutions containing pyrrolizidine alkaloids with

other members of their colony via trophallaxis (Reinhard et al. 2009). Detzel and Wink (1993)

found that there was no relationship between the ability of bees to detect compounds and their lethality, but some compounds, like alkaloids, had lower thresholds of detection and were also more lethal than others (e.g. glycosides). The threshold for detection of most of these compounds was between 100-1000 ppm. Bumblebees are also reported to have a low detection threshold for some secondary metabolites in sucrose solutions, including cardenolides or cardiac glycosides (Manson et al. 2012), diterpenoids (Tiedeken et al. 2014), alkaloids (Baracchi et al. 2015), and even pesticides present in nectar (Kessler et al. 2015b). All these studies illustrate that bees encountering secondary metabolites in nectar may be exposed to potential harm that could have consequences for individuals or colonies.

In situations where insect pollinators have difficulty initially detecting secondary metabolites in nectar, they have other mechanisms that enable them to avoid being poisoned. For example, honeybees learn to associate floral cues such as odours with the post-ingestive consequences of consuming toxins (Wright et al. 2010). This form of learning takes time, however, and requires bees to forage repeatedly to experience the same cues in association with nectar containing the toxin. In circumstances where bees are trained to associate one odour with a sucrose solution and another odour with sucrose containing a toxic secondary metabolite (e.g. amygdalin), they will 
generalise the symptoms of malaise caused by ingesting the toxin to both odours (Wright et al. 2010).

The consequence of nectar being repellent or having negative post-ingestive consequence for the pollinator would also be negative for a plant species if pollinators learned to avoid its flowers. This effect would likely be selected against with the result that, where present, nectar compounds are likely to be at concentrations that are undetectable (Tiedeken et al., 2014) or do not have immediate negative consequences for pollinators. They might also play other roles in plantpollinator interactions that benefit pollinators and the plant. Grayanotoxin I, for example, may benefit bumblebees by reducing the competition from other pollinating species that are intoxicated or repelled by grayanotoxins in Rhododendron ponticum nectar and enhance pollination efficiency of the host (Tiedeken et al. 2016).

Alkaloids provide examples of secondary metabolites that may optimise pollination service although they may not necessarily benefit the pollinators. Caffeine can act as a drug that affects the insect nervous system to alter behaviour (Wright et al. 2013). When honeybees consume nectar-relevant doses of caffeine in a sucrose solution during olfactory learning, they are more apt to remember the odour associated with reward than when given sucrose alone (Wright et al. 2013). Caffeine in food also affects the fidelity and persistence of bees returning to food sources containing the compound (Couvillon et al. 2015; Thomson et al. 2015). However, they may continue to return to the source of caffeinated food after the food has been removed (Couvillon et 
al. 2015), which suggests that memory of the location of food remains strong, potentially to the disadvantage of the pollinator.

Nicotine could also amplify the rewarding properties of nectar because it is an agonist of nicotinergic acetylcholine receptors (nAChRs) involved in fast neurotransmission between neurons. In particular, nAChRs are located in dopamine neurons governing reward in the vertebrate (Hyman et al. 2006) and insect brain (Barnstedt et al., 2016). Indeed, several studies have shown that nicotine and nicotine-like compounds have pharmacological effects on pollinator behaviour. Free-flying honeybees and bumblebees show preferences for sucrose solutions containing concentrations of nicotine $<15 \mu \mathrm{M}$ (Singaravelen et al. 2005; Baracchi et al. 2015), but they can detect and are repelled by concentrations greater than this (Singaravelen et al. 2005, Köhler et al. 2012, Tiedeken et al., 2014).

In summary, Paracelsus' proclamation that "Poison is in everything, and no thing is without poison. The dosage makes it either a poison or a remedy" highlights how important levels of exposure are to the effects of secondary metabolites on pollinators. Caffeine in floral nectar is a good example of this. One study showed that free-flying honeybees choose to consume sucrose solutions containing caffeine only when the concentration is $\sim 0.1 \mathrm{mM}$ or less (Singaravelen et al. 2005). Subsequent experiments using proboscis extension assays showed that honeybees can detect concentrations of caffeine greater than $10 \mathrm{mM}$ (Mustard et al. 2012; Wright et al. 2013). Interestingly, the amount of caffeine found in the floral nectar of Coffea and Citrus species is on average less than $0.3 \mathrm{mM}$ (Wright et al. 2013). Thus, the responses to secondary metabolites in nectar are highly dependent on the concentrations (Manson et al. 2013) and the pollinator species (Tiedeken et al. 2016). Broad generalizations about the biological activities of plant compounds 
on large taxonomic groups may, therefore, be inaccurate (Baker \& Baker 1975; Rhoades \& Bergdhal, 1981).

\section{Role of secondary metabolites in maintaining nectar quality and ameliorating bee diseases}

Besides their pharmacological effects on the brain and other pollination enhancing effects, secondary metabolites in nectar may provide other benefits to pollinators that would favour the selection for these compounds in plants. Effects on pollinator performance could also include the impact of secondary metabolites on biotic interactions (Forbey \& Hunter 2012). In particular, the potential role of secondary metabolites in plant-pollinator-microbe interactions was recognised in Adler's (2001) anti-microbial hypothesis. Secondary metabolites may prevent spoilage of nectar by microbes (an indirect benefit through the maintenance of nectar quality) or may reduce the impact of pathogens (a direct benefit for pollinator health). However, the evidence for both of these needs strengthening.

Nectar is a rich medium for microbial growth, and is easily contaminated with yeasts and bacteria, transferred on the bodies of bees and other floral visitors (Herrera et al. 2009; Fridman et al. 2011). Microbial enzymes hydrolyze sucrose and may also preferentially metabolise glucose or fructose, leading to imbalance in the carbohydrate ratio and reduced carbohydrate reward (Herrera et al. 2008; Vannette et al. 2013). Microbial contamination also alters the amino acid composition of nectar (Peay et al. 2012). These changes in nectar chemistry may affect pollinator attraction and ultimately plant fitness (see for example Schaeffer and Irwin 2014). However, these possible effects are complicated by the presence of secondary metabolites in 
nectar, which are expected to make it a less hospitable environment for microbes. Antimicrobial effects were tested by Fridman et al. (2011) who examined the nectars of three plant species Amygdalus communis, Citrus paradisi and Nicotiana glauca. Although these three species showed distinct nectar bacterial communities there was no effect of added amygdalin, caffeine and nicotine on the growth of bacterial isolates. Moreover, the yeast Candida gelsemii was isolated from the toxic nectar of Gelsemium sempervirens containing the alkaloid gelsemine (Manson et al. 2007). Recently, Vanette \& Fukami (2016) tested the effects of five compounds (catalpol, aucubin, caffeine, nicotine and ouabain) in synthetic nectar and found rather mixed effects on microbial growth and nectar chemistry. Interestingly, they also found that microbes reduced the concentration of some compounds in nectar. Different pyridine alkaloids in Nicotiana nectar affect the richness and composition of its bacterial communities, with nicotine having the strongest antimicrobial effect (Aizenberg-Gershtein et al. 2015). It is evident that interactions with microbes add a new level of complexity to the potential ecological functions of secondary metabolites in nectar.

There are other defence chemicals in nectar with protective functions (Heil 2011; Seo et al. 2013). Nectar proteins or nectarins in the nectar of ornamental tobacco plants protect plant tissue from invasion by pathogens (Carter \& Thornburg 2004). These antimicrobial enzymes produce strong oxidants, such as hydrogen peroxide at levels up to $4 \mathrm{mM}$, via the nectar redox cycle (Park \& Thornburg 2009). Seo et al. (2013) recently characterised the nectar proteome of Nicotiana attenuata, showing natural variation across the plant's native habitat. Other defencerelated proteins, including a lectin, have been identified in leek nectar (Peumans et al. 1997). Non-protein amino acids are also widespread in nectar and their functions are generally 
unknown, but they could play a similar role (Nepi, 2014). The extrafloral nectar of Acacia species, especially when ant protection is involved, contains an assortment of proteins with antimicrobial activity (Gonzalez-Teuber et al. 2009). Most work in this area is limited to tobacco plants but a broader study of nectar proteins could reveal enzyme activities that influence the ecological function of nectar for pollinators and even regulate chemical content through local biosynthetic modifications.

There is some evidence that secondary metabolites in nectar could benefit pollinators by increasing their resistance to parasite and pathogen infection. Almost all of these studies have involved bumblebees infected with Crithidia bombi, a trypanosomatid gut parasite. Manson et al (2010) assessed the effect on this interaction of gelsemine from G. sempervirens: consumption of gelsemine in artificial nectar by Bombus impatiens reduced pathogen loads after infection, but pre-exposure of the pathogen to gelsemine did not significantly reduce infection. In contrast, grayanotoxins did not protect $B$. terrestris audax against $C$. bombi (Tiedeken et al. 2016) and nicotine had only weak effects against the same pathogen in the same host (Baracchi et al. 2015); dietary nicotine did not clear the infection, and pre-exposure of the pathogen to nicotine did not affect its viability. Richardson et al. (2015) tested eight naturally occurring nectar chemicals, also in the B. impatiens-Crithidia system, of which half reduced the parasite load of bees that were inoculated and kept individually. Anabasine had the strongest effect but microcolonies provisioned with it did not respond to infection by increasing their consumption of this alkaloid. In a subsequent study (Richardson et al. 2016), B. impatiens infected with C. bombi foraged for longer at flowers of Chelone glabra with high iridoid glycoside concentrations in their nectar, resulting in benefits for plant reproduction. 
The review by McArt et al. (2014) of floral traits and the transmission of plant and animal pathogens shows how much more is known on the plant pathology side. There is a need for studies that examine the role of nectar toxins in pathogen transmission and infection intensity in systems other than Bombus-Crithidia, particularly for emerging diseases and in diseases that are crossing between species and which could have serious impacts on pollinator health at landscape scales (Fuerst et al. 2014).

Activity of plant toxins against disease agents suggests the possibility of self-medication behaviour (de Roode et al. 2013): parasitised pollinators may consume more alkaloids or other toxins in nectar or pollen. There are rigorous criteria for establishing that a behaviour is a form of self-medication (Singer et al. 2009): it should improve the fitness of infected animals, whereas in the absence of infection it should decrease fitness, and infection should trigger this behaviour (also see de Roode et al. 2013). Even in herbivores, there are few studies that meet these criteria (Forbey \& Hunter 2012). Among pollinators, Baracchi et al. (2015) looked for self-medication behaviour in bumblebees parasitised with $C$. bombi and provided with nicotine, but found contradictory results. In more general terms, collection of resins to make propolis contributes to the 'social immunity' of honey bees and has been shown to decrease the investment of individual bees in immune function (Simone et al. 2009). Colonies challenged with a fungal parasite (chalkbrood) increased their resin foraging rates (Simone-Finstrom \& Spivak 2012). It is likely that pollinators achieve some level of protection by selecting a mixed pollen diet that includes both the correct blend of nutrients and also secondary compounds that confer disease resistance. This also applies to collecting diverse nectar sources: Erler et al. (2014) showed strong 
antimicrobial activity of polyfloral honey compared to monofloral honeys. Erler and Moritz (2015) point out the advantage of eusociality in enabling storage of antimicrobial substances in floral resources for times when the appropriate plants are not in flower.

\section{Metabolic resistance to nectar toxins}

Animals have several biochemical and physiological mechanisms for dealing with xenobiotics after ingestion (Foley \& Moore 2005; Despres et al. 2007; Irwin et al. 2014). For some of these potential mechanisms there is little information available for pollinators compared to herbivores (Irwin et al. 2014). For example, we could find only one example of a pollinator sequestering nectar toxins: the adult danaid butterflies that feed on milkweeds as larvae sequester pyrrolizidine alkaloids from nectar (de Oliveira et al. 2015). Biotransformation processes used to avoid self-poisoning by pyrrolizidine alkaloids are summarised by Hartmann (2004). Gosselin et al. (2013) looked for possible sequestration of alkaloids from Aconitum (Ranunculaceae) in tissues of bumblebees, but found only trace levels in the specialist species and none in the generalist.

The most important mechanisms behind the tolerance of animals to toxins involve metabolism and elimination of these compounds. Excretion of toxic compounds frequently requires their prior enzymatic conversion to less toxic and more water-soluble forms. Detoxification pathways in honey bees, as in other animals, can be divided into phase I (functionalization, often involving oxidation to render the toxin more soluble), phase II (conjugation to a carrier molecule) and phase III (excretion): these are reviewed by Berenbaum \& Johnson (2015). The most prominent 
enzyme superfamilies that are responsible for the metabolism of toxins are the cytochrome P450 monooxygenases (P450s), glutathione transferases (GSTs) and carboxylesterases (Li et al. 2007). Sequencing of the honey bee genome demonstrated the relative paucity of genes associated with xenobiotic metabolism (Claudianos et al. 2006). Cytochrome P450 enzymes in honey bees are induced by pesticide treatment (Johnson et al. 2012) and by constituents of honey (Mao et al. 2013): addition of p-coumaric acid (a component of pollen grains, found in honey) to a sucrose diet enhanced the detoxification of coumaphos.

The molecular basis of nicotine detoxification has been investigated in adult and larval honey bees (du Rand et al. 2015; du Rand 2015). Proteomic and metabolomic analysis showed active detoxification of nicotine (three days exposure to $300 \mu \mathrm{M}$ ) in adults and larvae, associated with increased energetic investment and antioxidant and general stress responses. In larvae, two P450s were upregulated, and growth and development pathways were also affected. The metabolic fate of nicotine in adults was explored using radiolabelled nicotine and LC-MS analysis to identify its known catabolites (du Rand 2015). Unlike larvae of the tobacco specialist Manduca sexta in which most ingested nicotine is rapidly excreted unmodified (Snyder et al. 1994), honey bees convert nicotine into several phase I metabolites with 2'C-oxidation of nicotine being the main catabolic pathway. Young workers in cages (or in the hive) do not defaecate and these nicotinederived metabolites accumulate in the rectum. The energetic costs associated with nicotine detoxification in honey bees may well apply to other pollinators and the processing of other xenobiotics. Nicotine is of special interest because of the structural similarity with synthetic neonicotinoids, the most widely used insecticides worldwide. Cross-resistance to plant toxins and insecticides (specifically nicotine and neonicotinoids) is apparent in nicotine-tolerant strains 
of two insect pests: the peach-potato aphid Myzus persicae (Bass et al. 2013) and the tobacco whitefly Bemisia tabaci (Kliot et al. 2014). On a broader scale, Despres et al. (2007) discuss the ecological and evolutionary significance of such cross-resistance.

Pollinators may also have enzymes in saliva, the crop or the gut that break down secondary metabolites. One would predict that conversion of nectar to honey by honeybees should lead to increased concentrations of any secondary metabolites present provided the compounds do not undergo natural degradation. Lectin in leek nectar is lost during processing into honey (Peumans et al. 1997), as are phenolics in nectar of Aloe littoralis (Liu et al. 2007), amygdalin in almond nectar (London-Shafir et al. 2003), and nicotine when included in artificial nectar for bees (Singaravelan et al. 2006). The mechanisms are unknown, but a simple explanation is that these compounds have been metabolised or are labile in these conditions. To verify this, researchers should check for breakdown products in honey as well as the original compounds. Whether this detoxification occurs in the bees or the hive environment (Naef et al. 2004; Liu et al. 2007) is not clear. Berenbaum \& Johnson (2015) use the term 'social detoxification' for various honey bee behaviours that may reduce the need for enzymatic detoxification. These include collecting from diverse pollen and nectar sources to dilute particular toxins, and subsequent food processing in the colony, where the production of honey and bee bread may lead to degradation of toxins.

\section{Future directions.}

Pollen was outside the scope of this review, largely because the ecological functions or detrimental effects of pollen secondary metabolites have been overlooked save for a few examples (Arnold et al. 2014). This is despite evidence suggesting potentially important 
negative ecological consequences for pollinators consuming toxic pollen (Haider et al. 2013). Concentrations of potential toxins are often higher in pollen than nectar (London-Shafir et al. 2003, Cook et al. 2013; Irwin et al. 2014); therefore, since the biological effects of secondary metabolites are typically dose dependent, the detrimental effects of pollen toxins on pollinators could be more severe than those of nectar toxins. The protection of pollen makes sense since it is the male gamete. Because pollen is also the primary source of protein and other nutrients for many pollinating insects but especially bees and their larvae (Michener 2007), its toxicity could impose colony level effects as suggested by Arnold et al. (2014). Oligolectic species may specialise on pollen of a few species or genera while other species are generalists (polylectic) (Cane and Sipes 2006) but the role of plant chemicals in pollen in mediating these behaviours is still unclear and needs attention. Ultimately pollen is a source of large quantities of plant secondary metabolites for pollinators and any long term colony or population benefits such as in ameliorating disease or toxic effects may be as important as those reported for nectar secondary metabolites.

Most new studies on the secondary metabolites encountered by pollinators in floral rewards have concerned nectar and consequently this has been the focus of the present paper, particularly the evidence supporting adaptive functions for these metabolites in nectar. Most research to date is focused on alkaloids of bee-pollinated species (Elliott et al. 2008; Koehler et al. 2012; Cook et al. 2013; Gosselin et al. 2013; Irwin et al. 2014; Tiedeken et al. 2014) which could be partly because these compounds are used by humans (Ott 1998). High profile plant species with well documented toxicities to humans make compelling targets for study but may not necessarily be the most informative examples. Less than $10 \%$ of plant nectars studied contain alkaloids while more than $30 \%$ contain phenolics and $50 \%$ reportedly contain non-protein amino acids (Baker, 
1977). Phenolics include stilbenes, isoflavonoids and benzofurans which have proven antifungal and trypanocidal activities (Aslam et al. 2009; Getti et al. 2006); so they may also have greater potential than alkaloids in the search for compounds that reduce levels of infection by Crithidia and Nosema (Baracchi et al., 2015; Richardson et al., 2015).

While there is now evidence demonstrating that nectar chemicals modulate pollinator behaviour for the benefit of the plant (Wright et al. 2015; Couvillon et al. 2015, Thomson et al. 2015), whether these effects improve plant fitness is still largely unsubstantiated and needs attention. Recent evidence from Rhododendron ponticum suggests that diterpenoid grayanotoxins in nectar that are selectively toxic to bees may filter out generalists (Tiedeken et al. 2016). Rhododendron ponticum is an invasive species in the British Isles but native to the Iberian Peninsula. The concentration of these nectar toxins is either significantly lower or absent in established populations in the invasive range (Egan, 2015). Poorly adapted pollinators in the invasive range may select for reduced nectar toxins. This hypothesis is supported by a positive correlation between plant fitness as a measure of seed set with toxin concentration in the native population and a negative correlation in the invasive population (Egan 2015; Egan et al. 2016). Furthermore, correlations between nectar chemistry and pollination syndromes across the whole Rhododendron genus provide support for toxic nectar selection (Egan 2015). Elsewhere, evidence from $N$. attenuata suggests that repellence of nicotine to hummingbirds increases flower visits but the unpredictable variation in nicotine among flowers within populations and even on the same plant prevents complete deterrence. Plants with nicotine in their nectar had a greater number of genetically different sires, compared to plants in which nicotine production had been 'switched off' (Kessler et al. 2012). Where nectaries are concealed in specialist syndrome flowers for all but a few pollinators, nectar robbery or larceny may occur. The 
evidence in some examples that nectar alkaloids protect nectar from robbery is weak. For example, Gosselin et al. (2013) use the occurrence of trace amounts of aconitine type alkaloids in the body of a specialist long-tongued bumblebee and its absence from a short-tongued generalist and potential larcenist as evidence for the role of these compounds in conserving nectar for the specialist. This work did not evaluate field visitation of the two target species of bees to the plant; behavioural data is also required as evidence that they differ in their response to the toxin or its repellent effects. While Adler and Irwin (2005) report that artificial variation in nectar alkaloids is positively correlated with nectar robbery, elsewhere there is little evidence of relationships between nectar secondary metabolites and robbing in natural systems, and in the case of Aconitum it is not clear from Gosselin et al. (2013) if the protection of nectaries is afforded by components in the nectar or components in the corolla.

The impact of secondary metabolites on pollinator species other than honeybees and one or two other model bee species (e.g., Bombus impatiens or B. terrestris) is a limiting factor, particularly since wild pollinators contribute significantly to food production and resilience of ecosystems (Garibaldi et al. 2013). For example, Tiedeken et al. (2016) showed that grayanotoxin I in $R$. ponticum nectar is highly toxic to honeybees from the British Isles but not toxic to Bombus terrestris audax, the UK subspecies of B. terrestris. However, importantly they also evaluated the toxicity against a mining bee species (Andrena scotica) and showed potent negative but sublethal effects that suggest impacts of toxic nectars in invasive species could have wider implications for pollinators. 
One additionally overlooked area is the role of the bee microbiome, particularly considering the importance of a healthy microbiome underpinning stronger disease tolerance (Koch and SchmidHempel 2012). We therefore predict that understanding the role of bacteria and yeasts in modifying secondary metabolites from nectar and pollen or alternatively being compromised by them (Vannette and Fukami 2016) could shed more light on how secondary metabolites influence pollinator behaviour or health. For example, Ceja-Navarro et al. (2015) report that caffeine is detoxified by the gut bacteria of the coffee berry borer, which enables this serious pest insect to otherwise colonise coffee beans. It is possible that bacterial symbionts in bees and other pollinators may provide mechanisms to detoxify plant metabolites and enable pollinators to tolerate nectar toxins. Further, the role of nectar secondary metabolites as a component of multimodal signals, including volatiles and flower colour, constitutes a largely overlooked area of research (Parachnowitsch and Manson 2015).

The multi-organismal reality of interactions mediated by secondary metabolites and the multitude of chemicals encountered in nectar add layers of complexity to this research domain. Moreover, variation in concentrations of compounds across time and space and even on the same plant is largely unexplained and makes predictions of ecological function more difficult. We predict an emerging prominence of phylogenetics and comparative genomics systems biology, metabolic engineering and neuroscience for studying pollinator plant interactions and the genetics underlying the chemistry of nectar and pollen and how the occurrence of secondary metabolites in nectar is regulated (Kang and Baldwin 2008; Lin et al. 2014; Manson et al. 2012). This last point is particularly pertinent. Evidence that nectar secondary metabolites are regulated by the plant and are associated with plant fitness is required to demonstrate that all these fascinating potential effects are not simply the consequence of chemical biosynthesis elsewhere 
in the plant. Gene silencing techniques have been used to demonstrate how nectar chemicals optimise outcrossing (Kessler et al., 2012) and a stronger understanding of the chemistry and interactions with pollinators will ultimately provide more evidence for ecological functions in nectar and pollen. This will require large scale analysis of species across landscapes and time to fully understand the phenology of floral chemistry (Egan et al., 2016).

\section{Acknowledgements}

The authors would like to thank the Royal Society of London and the National Research Foundation of South Africa for the international workshop award (UK-South Africa Seminars, SA140017) that funded the collaborative meeting that led to this review.

\section{References.}

Adler, L.S. (2001) The ecological significance of toxic nectar. Oikos, 91, 409-420.

Adler, L. S. \& Irwin, R. E. (2005) Ecological costs and benefits of defenses in nectar. Ecology, 86, 2968-2978.

Adler, L. S., Wink, M., Distl, M. \& Lentz, A. J. (2006) Leaf herbivory and nutrients increase nectar alkaloids. Ecology Letters, 9, 960-967. 
Adler, L.S., Seifert, M.G. Wink, M. \& Morse G.E. (2012) Reliance on pollinators predicts defensive chemistry across tobacco species. Ecology Letters, 15, 1140-1148.

Aizenberg-Gershtein, Y., Izhaki, I., Santhanam, R., Kumar, P., Baldwin, I.T., \& Halpern, M. (2015) Pyridine-type alkaloid composition affects bacterial community composition of floral nectar. Scientific Reports, 5, 11536.

Agrawal, A.A. \& Weber M.G. (2015) On the study of plant defence and herbivory using comparative approaches: how important are secondary plant compounds. Ecology Letters, 18, 985-991

Anton, S. \& Kaminska M. (2015) Comparative floral spur anatomy and nectar secretion in four representatives of Ranunculaceae. Protoplasma, 252, 1587-1601.

Arnold S.E.J., Peralta Idrovo, M.E., Lomas Arias' L.J., Belmain, S.R. \& Stevenson, P.C. (2014). Herbivore defence compounds occur in pollen and reduce bumblebee colony fitness. Journal of Chemical Ecology, 40, 878-881.

Aslam, S.N., Stevenson, P.C., Kokubun, T. \& Hall, D.R. (2009) Antibacterial and antifungal activity of cicerfuran and related 2-arylbenzofurans and stilbenes. Microbiological Research, 164, 191-195. 
Aurorès-Weber, A., de Brito Sanchez, M.G., Giurfa, M. \& Dyer, A.G. (2010) Aversive reinforcement improves visual discrimination learning in free-flying honeybees. PLoS One, 5, e15370.

Baker, H. G. \& Baker, I. (1975). Studies of nectar-constitution and pollinator-plant coevolution. In: Coevolution of plants and animals. (eds L. E. Gilbert \& P. H. Raven), Univ. of Texas Press, pp. $100-140$.

Baker, H. G. (1977) Non-sugar chemical constituents of nectar. Apidologie, 8, 349-356.

Baracchi, D., Brown, M.F.J. \& Chittka, L. (2015) Weak and contradictory effects of selfmedication with nectar nicotine by parasitized bumblebees. F1000 Research, doi: 10.12688/f1000research.6262.3

Barnstedt, O., Owald, D., Felsenberg,J., Brain, R. Moszynski, J-P., Talbot, C.B. et al. (2016) Memory-relevant mushroom body output synapses are cholinergic. Neuron, 89, 1-11.

Bass, C., Zimmer, C.T., Riveron, J.M., Wilding, C.S., Wondji, C.S., Kaussmann, M., et al. (2013) Gene amplification and microsatellite polymorphism underlie a recent insect host shift. Proceedings of the National Academy of Science, USA, 110, 19460-19465.

Berenbaum, M.R. (1995). The chemistry of defense - theory and practice. Proceedings of the National Academy of Science, USA, 92, 2-8. 
Berenbaum, M.R. \& Johnson, R.M. (2015) Xenobiotic detoxification pathways in honey bees. Current Opinion in Insect Science, 10, 51-58.

Campbell, S.A. (2015) Ecological mechanisms for the coevolution of mating systems and defence. New Phytologist, 205, 1047-1053.

Cane, J.H. \& Sipes, S. (2006) Characterizing floral specialization by bees: Analytical methods and a revised lexicon for oligolecty. Plant-pollinator interactions: from specialization to generalization. (eds N.M. Waser \& J. Ollerton) pp 99-122, The University of Chicago Press, Chicago.

Carter, C.J., \& Thornburg, R.W. (2004) Tobacco Nectarin V is a flavin-containing berberine bridge enzyme-like protein with glucose oxidase activity. Plant Physiology, 134, 460-469.

Cawoy, V., Kinet, J.M., \& Jacquemart, A.L. (2008) Morphology of nectaries and biology of nectar production in the distylous species Fagopyrum esculentum. Annals of Botany, 102, 675-684.

Claudianos, C., Ranson, H., Johnson, R.M., Biswas, S., Schuler, M.A., Berenbaum, M.R., Feyereisen, R. \& Oakeshott, J.G. (2006) A deficit of detoxification enzymes: pesticide sensitivity and environmental response in the honeybee. Insect Molecular Biology, 15, 615-636. 
Cook, D., Manson, J. S., Gardner, D. R., Welch, K. D., \& Irwin, R. E. (2013) Norditerpene alkaloid concentrations in tissues and floral rewards of larkspurs and impacts on pollinators. Biochemical Systematics and Ecology, 48, 123-131.

Couvillon, M.J., Al Toufailia, H., Butterfield, T.M., Schrell, F., Ratnieks, F.L.W. \& Schurch R. (2015) Caffeinated forage tricks honeybees into increasing foraging and recruitment behaviours. Current Biology, 25, 1-4.

Detzel, A. \& Wink, M. (1993) Attraction, deterrence or intoxication of bees (Apis mellifera) by plant allelochemicals. Chemoecology, 4, 8-18.

Després, L., David, J.-P. \& Gallet, C. (2007) The evolutionary ecology of insect resistance to plant chemicals. Trends in Ecology and Evolution, 22, 298-307.

Du Rand, E.E. (2015) Molecular mechanisms underlying xenobiotic tolerance in the honey bee, Apis mellifera scutellata. $\mathrm{PhD}$ thesis, University of Pretoria.

Du Rand, E.E., Smit, S., Beukes, M., Apostolides, Z., Pirk, C.W.W. \& Nicolson, S.W. (2015) Detoxification mechanisms of honey bees (Apis mellifera) resulting in tolerance of dietary nicotine. Scientific Reports, 5, 11779.

Egan P. (2015) Chemical ecology and conservation biogeography of Rhododendron ponticum L. PhD Thesis. Trinity College, Dublin. 
Egan, P.A., Stevenson, P.C., Wright, G.A., Boylan, F, Stout, J.C. (2016) Toxic nectar varies at multiple spatial scales and in response to plant invasion. Journal of Ecology, 104, 1106-1115.

Erler, S., Denner, A., Bobis, O., Forsgren, E. \& Moritz, R.F.A. (2014) Diversity of honey stores and their impact on pathogenic bacteria of the honeybee, Apis mellifera. Ecology and Evolution, 20, 3960-3967.

Erler, S. \& Moritz, R.F.A. (2015) Pharmacophagy and pharmacophory: mechanisms of selfmedication and disease prevention in the honeybee colony (Apis mellifera). Apidologie, doi: 10.1007/s13592-015-0400-z.

Foley, W.J. \& Moore, B.D. (2005) Plant secondary metabolites and vertebrate herbivores - from physiological regulation to ecosystem function. Current Opinion in Plant Biology, 8, 430-435.

Forbey, J.S. \& Hunter, M.D. (2012) The herbivore's prescription: a pharm-ecological perspective on host-plant use by vertebrate and invertebrate herbivores. The ecology of plant secondary metabolites: from genes to global processes (eds G.R. Iason, M. Dicke \& S.E. Hartley), pp. 78-100. Cambridge University Press, Cambridge.

Fraenkel, G.S. (1959) Raison d'etre of secondary plant substances. Science, 129, 1466-1470. 
Fridman, S., Izhaki, I., Gerchman, Y. \& Halpern, M. (2012) Bacterial communities in floral nectar. Environmental Microbiology Reports, 4, 97-104.

Fürst, M.A., McMahon, D.P., Osborne, J.L., Paxton, R.J. \& Brown, M.J.F. (2014) Disease associations between honeybees and bumblebees as a threat to wild pollinators. Nature, 506, $10.1038 /$ nature 12977.

Garibaldi, L. A., Steffan-Dewenter, I., Winfree, R., Aizen, M. A., Bommarco, R., Cunningham, S. A., et al. (2013) Wild pollinators enhance fruit set of crops regardless of honey bee abundance. Science, 339, 1608-1611

Gegear, R.J., Manson, J.S. \& Thomson, J.D. (2007) Ecological context influences pollinator deterrence by alkaloids in floral nectar. Ecology Letters, 10, 375-382.

Getti, G. T. M., Aslam, S. N., Humber, D. P., Stevenson, P. C. \& Cheke, R. A. (2006) The effect of cicerfuran, an aryl benzofuran from Cicer bijugum, and related benzofurans and stilbenes on Leishmania aethiopica, L. tropica and L. major. Planta Medica, 72, 907-911.

González-Teuber, M. \& Heil, M. (2009) Nectar chemistry is tailored for both attraction of mutualists and protection from exploiters. Plant Signalling and Behavior, 4, 809.

Gosselin, M., Michez, D., Vanderplanck, M., Roelants, D., Glauser, G. \& Rasmont, P. (2013) Does Aconitum septentrionale chemically protect floral rewards to the advantage of specialist bumblebees? Ecological Entomology, 38, 400-407. 
Haider, M., Dorn, S. \& Müller, A (2013) Intra- and interpopulational variation in the ability of a solitary bee species to develop on non-host pollen: implications for host range expansion. Functional Ecology, 27, 255-263.

Heil, M. (2011) Nectar: generation, regulation, and ecological functions. Trends in Plant Science, 16, 191-200.

Herrera, C.M., de Vega, C., Canto, A. \& Pozo, M.I. (2009) Yeasts in floral nectar: a quantitative survey. Annals of Botany, 103, 1415-1423.

Herrera, C.M., García, I.M. \& Pérez, R. (2008) Invisible floral larcenies: microbial communities degrade floral nectar of bumble bee-pollinated plants. Ecology, 89, 2369-2376.

Honda, Y., Honda, K., \& Omura, H. (2006) Major components in the hairpencil secretion of a butterfly, Euploea mulciber (Lepidoptera, Danaidae): their origins and male behavioral responses to pyrrolizidine alkaloids. Journal of Insect Physiology, 52, 1043-1053.

Inoue, T.A., Asaoka, K., Seta, K., Imaeda, D. \& Ozaki, M. (2009) Sugar receptor response of the food-canal taste sensilla in a nectar-feeding swallowtail butterfly, Papilio xuthus. Naturwissenschaften, 96, 355-363. 
Irwin, R.E., Cook, D., Richardson, L.L. \& Gardner, D.L. (2014) Secondary compounds in floral rewards of toxic rangeland plants: impacts on pollinators. Journal of Agricultural and Food Chemistry, 62, 7335-7344.

Johnson, R.M., Mao, W., Pollock, H.S., Niu, G., Schuler, M.A. \& Berenbaum, M.R. (2012) Ecologically appropriate xenobiotics induce cytochrome P450s in Apis mellifera. PLoS ONE, 7, e31051.

Jørgensen, K., Stranden, M., Sandoz, J.-C., Menzel, R. \& Mustaparta, H. (2007) Effects of two bitter substances on olfactory conditioning in the moth Heliothis virescens. The Journal of Experimental Biology, 210, 2563-2573.

Kaczorowski, R.L., Koplovich, A., Sporer, F., Wink, M. \& Markman, S. (2014) Immediate effects of nectar robbing by Palestine sunbirds (Nectarinia osea) on nectar alkaloid concentrations in tree tobacco (Nicotiana glauca). Journal of Chemical Ecology, 40, 325330.

Kessler, D., Bhattacharya. S., Diezel, C., Rothe, E., Gase, K., Schöttner, M. et al. (2012). Unpredictability of nectar nicotine promotes outcrossing by hummingbirds in Nicotiana attenuata. Plant Journal, 71, 529-538.

Kessler, D. Kallenbach, M., Diezel, C. Rothe, E. Murdock, M. Baldwin, I.T (2015a). How scent and nectar influence floral antagonists and mutualists. eLife 10.7554/eLife.07641. 
Kessler, S.C., Tiedeken, E.J., Simcock, K.L., Derveau, S., Mitchell, J., Softley, S., et al. (2015b) Bees prefer foods containing neonicotinoid pesticides. Nature, 521, 74-76.

Kevan, P.G. \& Baker, H.G. (1983) Insects as flower visitors and pollinators. Annual Review of Entomology, 28, 407-453.

Kliot, A., Kontsedalov, S., Ramsey, J.S., Jander, G. \& Ghanim, M. (2014) Adaptation to nicotine in the facultative tobacco-feeding hemipteran Bemisia tabaci. Pest Management Science, 70, 1595-1603.

Köhler, A., Pirk, C.W.W. \& Nicolson, S.W. (2012) Honeybees and nectar nicotine: deterrence and reduced survival versus potential health benefits. Journal of Insect Physiology, 58, 286-292.

Lerch-Henning, S. \& Nicolson, S. W. (2015) Effects of nicotine on the digestive performance of nectar-feeding birds reflect their relative tolerance to this alkaloid. Comparative Biochemistry and Physiology A, 190, 47-53.

Lerch-Henning, S. \& Nicolson, S.W. (2013) Bird pollinators differ in their tolerance of a nectar alkaloid. Journal of Avian Biology, 44, 408-416.

Lin, I.W, Sosso, D., Chen, L-Q., Gase, K., Kim, S-G, Kessler, D. et al. (2012) Nectar secretion requires sucrose phosphate synthases and the sugar transporter SWEET9. Nature, 508, 546549. 
Liu, F., Chen, J., Chai, J., Zhang, X., Bai, X., He, D. et al. (2007) Adaptive functions of defensive plant phenolics and a non-linear bee response to nectar components. Functional Ecology, 21, 96-100.

London-Shafir, I., Shafir, S. \& Eisikowitch, D. (2003) Amygdalin in almond nectar and pollen facts and possible roles. Plant Systematics \& Evolution, 238, 87-95.

Manson, J.S., Lachance, M.-A. \& Thomson, J.D. (2007) Candida gelsemii sp. nov., a yeast of the Metschnikowiaceae clade isolated from nectar of the poisonous Carolina jessamine. Antonie van Leeuwenhoek, 92, 37-42.

Manson, J.S., Cook, D., Gardner, D.R. \& Irwin, R.E. (2013) Dose-dependent effects of nectar alkaloids in a montane plant-pollinator community. Journal of Ecology, 101, 1604-1612.

Manson, J.S., Rasmann, S., Halitschke, R., Thomson, J.D. \& Agrawal, A.A. (2012) Cardenolides in nectar may be more than a consequence of allocation to other plant parts: a phylogenetic study of Asclepias. Functional Ecology, 26, 1100-1110.

Manson, J.S., Otterstatter, M.C. \& Thomson, J.D. (2010) Consumption of a nectar alkaloid reduces pathogen load in bumble bees. Oecologia, 162, 81-89. 
Mao, W., Schuler, M.A. \& Berenbaum, M.R. (2013) Honey constituents up-regulate detoxification and immunity genes in the western honeybee Apis mellifera. Proceedings of the National Academy of Science, USA, 110, 8842-8846.

Marlin, D., Nicolson, S.W., Yusuf, A.A., Stevenson, P.C., Heyman, H.M. \& Krüger, K. (2014) The only African wild tobacco, Nicotiana africana: alkaloid content and the effect of herbivory. PLoS One, 9, e102661.

McCall, A.C. \& Fordyce, J. A. (2010) Can optimal defence theory be used to predict the distribution of plant chemical defences? Journal of Ecology, 98, 985-992.

McKey, D. (1974) Adaptive patterns of in alkaloid physiology. American Naturalist, 108, 305320.

Naef, R., Jaquier, A., Velluz, A. \& Bachofen, B. (2004) From the linden flower to linden honey volatile constituents of linden nectar, the extract of bee-stomach and ripe honey. Chemistry and Biodiversity, 1, 1870-1879.

Nepi, M. (2014) Beyond nectar sweetness: the hidden ecological role of non-protein amino acids in nectar. Journal of Ecology, 102, 108-115.

Nepi M., (2007). Nectary structure and ultrastructure Nectaries and Nectar (eds S.W. Nicolson, M. Nepi \& E. Pacini) pp. 129-166. Springer: Dordrecht. 
de Oliveira, M.V., Trigo, J.R., Rodrigues, D. (2015) Southern monarchs do not develop learned preferences for flowers with pyrrolizidine alkaloids. Journal of Chemical Ecology, 41, 662669

Orona-Tamayo, D., Wielsch, N., Escalante-Pe'rez, M., Svatos, A., Molina-Torres, J., Muck, A., et al. (2013) Short-term proteomic dynamics reveal metabolic factory for active extrafloral nectar secretion by Acacia cornigera ant-plants. The Plant Journal, 73, 546-554.

Ômura, H., Honda, K., Asaoka, K. \& Inoue, T.A. (2008) Tolerance to fermentation products in sugar reception: Gustatory adaptation of adult butterfly proboscis for feeding on rotting foods. Journal of Comparative Physiology A, 194, 545-555.

Ott,J. (1998) The Delphic bee: bees and toxic honeys as pointers to psychoactive and other medicinal plants. Economic Botany, 52, 260-266.

Ou, P. Hasegawa, S., Herman, Z. \& Fong, C.H. (1988) Limonoid biosynthesis in stems of Citrus limon. Phytochemistry, 27, 115-118.

Pacini E. \& Nepi, M. (2007) Nectar production and presentation. Nectaries and Nectar (eds S.W. Nicolson, M. Nepi \& E. Pacini) pp 167-214. Springer: Dordrecht.

Park, S \& Thornburg J.W. (2009). Biochemistry of nectar proteins Journal of Plant Biology, 52, 27-34. 
Peay, K.G., Belisle, M. \& Fukami, T. (2012) Phylogenetic relatedness predicts priority effects in nectar yeast communities. Proceedings of the Royal Society B, 279, 749-758.

Peumans, W.J., Smeets, K., Van Nerum, K., Van Leuven, F. \& Van Damme, E.J.M. (1997) Lectin and alliinase are the predominant proteins in nectar from leek (Allium porrum L.) flowers. Planta, 201, 298-302.

Pichersky, E. \& Gang D.R. (2000) Genetics and biochemistry of secondary metabolites in plants: an evolutionary perspective. Trends in Plant Science, 5, 439-445.

Pyke, G.H. (1991) What does it cost to a plant to produce floral nectar? Nature, 350, 58-59.

Raguso, R.A, \& Willis, M.A. (2005) Synergy between visual and olfactory cues in nectar feeding by wild hawkmoths, Manduca sexta. Animal Behaviour, 69, 407-418.

Rhoades, D.F. \& Bergdahl, J.C. (1981) Adaptive significance of toxic nectar. American Naturalist, 117, 798-803.

Richardson, L.L., Adler, L.S., Leonard, A.S., Andicoechea, J., Regan, K.H., Anthony, W.E., Manson, J.S. \& irwin, R.E. (2015) Secondary metabolites in floral nectar reduce parasite infections in bumblebees. Proceedings of the Royal Society B, 282, 20142471. 
Richardson, L.L., Bowers, M.D. \& Irwin, R.E. (2016) Nectar chemistry mediates the behavior of parasitized bees: consequences for plant fitness. Ecology, 97, 325-337.

Reiter, S., Campillo Rodriguez, C., Sun, K. \& Stopfer, M. (2015) Spatiotemporal coding of individual chemicals by the gustatory system. Journal of Neuroscience, 35, 12309-12321.

Schaeffer, R.N., Irwin, R.E. (2014) Yeasts in nectar enhance male fitness in a montane perennial herb. Ecology, 95, 1792-1798.

Schoonhoven, L.M.; van Loon, J. J.A. \& Dicke, M. (2005). Plant chemistry: endless variety. Insect-Plant Biology, pp3-82, University Press, Oxford, UK.

Seo, P. J., Wielsch, N., Kessler, D., Svatoš, A., Park, C.-M., Baldwin, I. T., et al. (2013). Natural variation in floral nectar proteins of two Nicotiana attenuata accessions. BMC Plant Biology, 13, 101.

Simone-Finstrom, M.D. \& Spivak, M. (2012) Increased resin collection after parasite challenge: a case of self-medication in honey bees? PLoS One, 7, e34501.

Simone, M., Evans, J.D. \& Spivak, M. (2009) Resin collection and social immunity in honey bees. Evolution, 63, 3016-3022.

Singaravelan, N., Ne'eman, G., Inbar, M. \& Izhaki, I. (2005) Feeding responses of free-flying honeybees to secondary compounds mimicking floral nectars. Journal of Chemical Ecology, 31, 2791-2804. 
Singaravelan, N., Inbar, M., Ne'eman, G., Distl, M., Wink, M. \& Izhaki, I. (2006) The effects of nectar-nicotine on colony fitness of caged honeybees. Journal of Chemical Ecology, 32, 49-58.

Singer, M.S., Mace, K.C. \& Bernays, E.A. (2009) Self-medication as adaptive plasticity: increased ingestion of plant toxins by parasitized caterpillars. PLos ONE, 4(3), e4796.

Snyder, M.J., Walding, J.K. \& Feyereisen, R. (1994) Metabolic fate of the allelochemical nicotine in the tobacco hornworm Manduca sexta. Insect Biochemistry and Molecular Biology, 24, 837-846.

Thomson, J. D., Draguleasa, M.A., Tan, M.G. (2015) Flowers with caffeinated nectar receive more pollination Arthropod-Plant Interactions, 9, 1-7.

Tiedeken, E-J, Stout, J.C, Egan, P., Stevenson, P.C., Wright G.A. (2014) Bumblebees are not deterred by ecologically relevant concentrations of nectar toxins. Journal of Experimental Biology, 217, 1620-1635.

Tiedeken E-J., Egan, P.A., Stevenson, P.C., Wright, G.A., Brown, M.J.F., Power, E.F., et al. (2016) Nectar chemistry modulates the impact of invasive plant species on native pollinators. Functional Ecology, 30, 885-893. 
Vannette, R.L. \& Fukami, T. (2016) Nectar microbes can reduce secondary metabolites in nectar and alter effects on nectar consumption by pollinators. Ecology, 97, 1410-1419.

Vannette, R.L., Gauthier, M.-P.L. \& Fukami, T. (2012) Nectar bacteria, but not yeast, weaken a plant-pollinator mutualism. Proceedings of the Royal Society B, 280, 20122601.

Verpoorte, R. (2000) Secondary metabolism. Metabolic engineering of plant secondary metabolism, (eds. R. Verpoorte, \& A. W. Alfermann) pp. 1-29. Kluwer, Dordrecht, The Netherlands.

Whittaker, R.H., Feeny P.P. (1971) Allelochemicals - chemical interactions between species, Science, 171, 757-770.

Wright, G.A., Mustard, J.A., Simcock, N.K., Ross-Taylor, A.A.R., McNicholas, L.D., Popescu, A. et al. (2010) Parallel reinforcement pathways for conditioned food aversions in the honeybee. Current Biology, 20, 2234-2240.

Wright, G. A., Baker, D., Palmer, M. J., Stabler, D., Mustard, J.D., Power, E., et al. (2013) Caffeine in floral nectar enhances a pollinator's memory of reward. Science, 339, 1202-1204.

Wright, G.A. \& Shiestl, F. (2009) The evolution of floral scent: the influence of olfactory learning by insect pollinators on the honest signaling of floral rewards. Functional Ecology, 23, 841851. 